\title{
Physicians' Response to Patients' Quality-of-Life Goals
}

\author{
Becky A. Purkaple, MD, Zsolt J. Nagykaldi, PhD, Arrash Allabyar, BS, \\ Robert Todd, MS, and James W. Mold, MD, MPH
}

Purpose: Patients are able to participate in quality-of-life (QOL) discussions, but clinicians struggle to incorporate this information into encounters and shared decision making. We designed a study to determine if a clinician-initiated prompt could make patient visits more goal directed.

Methods: Patients were given a previsit questionnaire that included QOL questions. Physicians in the control were given no further prompting. The intervention physicians were prompted to ask a QOL question: what things are you unable to do because of your health problems today? A 2-pronged design was used: 1 prepost group where 3 physicians participated in 5 control and 5 intervention encounters $(n=30)$ and a randomized group in which 11 physicians and their patients were randomly assigned to control or intervention groups $(n=30)$. Video recordings of the encounters were reviewed to determine if QOL goals were mentioned and if they were utilized in decision making.

Results: Fifty-seven (95\%) of the 60 patients provided written answers to at least 1 of the QOL questions on the intake form. QOL goals were mentioned during intervention encounters more often than in control groups. Q0L information was used in shared decision making in only 4 of the $30(13 \%)$ intervention encounters.

Conclusions: Physicians were able to engage in QOL discussions with their patients, but did not translate that information to medical decision making. More research is needed to understand why clinicians opt not to use QOL information and how to make communication more goal directed. (J Am Board Fam Med 2020;33:71-79.)

Keywords: Clinical Decision-Making, Communication, Patient Participation, Patient-Centered Care, Physicians, Quality-of-Life, Surveys and Questionnaires, Video Recording

A recent article in $\mathcal{F} A M A$ posited that health care needs a new specialty called interpersonal medicine. ${ }^{1}$ The proposed specialty would combine the tenets of evidence-based medicine with tailored

This article was externally peer reviewed.

Submitted 6 May 2019; revised 14 September 2019; accepted 17 September 2019.

From Family and Preventive Medicine, Springfield Family Medicine, Springfield, OR (BAP); Department of Family and Preventive Medicine, University of Oklahoma Health Sciences Center, Oklahoma City, OK (ZJN); University of Oklahoma College of Medicine, Oklahoma City, OK (AA, RT); George Lynn Cross Emeritus Professor of Family and Preventive Medicine, University of Oklahoma College of Medicine, Oklahoma City, OK (JWM)

Funding: none.

Conflict of interest: The authors certify that they have no affiliations with or involvement in any organization or entity with any financial interest or non-financial interest in the subject matter or materials discussed in this manuscript.

Corresponding author: Becky Purkaple, MD, 2280 Marcola Road, Springfield, OR 97477 (E-mail: beckyp@springfieldfam. com). care based on the "patient's circumstances, capabilities, and preferences." This is not a new idea. It was the primary reason for establishing the specialty of Family Medicine in $1969 .^{2}$ However, blending the science of medicine with person-centered care has proven more difficult than anticipated.

Many theoretical frameworks such as the aforementioned interpersonal medicine have been developed under the umbrella term: patient-centered care. Thousands of articles have been written in an attempt to better codify and understand this fundamental aspect of care, ${ }^{3}$ but it is hard to define. ${ }^{4}$ Broadly, patient-centered care is viewing the health care encounter not through the lens of the system, physician, or disease, but instead from the viewpoint of the individual. ${ }^{5,6}$ Care that is patient-centered has been shown to decrease health care utilization $^{7}$ and increase quality of care. ${ }^{8}$ It has been 
shown that patient participation in decision making improves patient outcomes in depression, cardiovascular disease, palliative care, and disability rehabilitation. ${ }^{9-12}$ A variety of approaches to patientcentered care have been described, but few offer a substantive praxis for truly shifting the focus of care to patient needs and priorities while providing a framework for the application of evidence-based clinical care. ${ }^{13-15}$

This study was based on an approach that proposes a way to do so. Goal-directed health care (GDHC) established by Dr. Mold and colleagues in $1991,{ }^{16}$ is a practical, clinically feasible way to apply the concept to current primary care settings in real time. GDHC is an alternate to the problembased approach that dominates the current American medical system. ${ }^{17,18}$ Problem-based care assumes that patients' health goals will be achieved when their medical problems have been solved. ${ }^{19,20}$ However, researchers have consistently shown relatively poor correlations between biomedical measures of disease severity and patient perceptions of quality of life (QOL). ${ }^{21-22}$

GDHC, by contrast, creates a framework within which to apply scientific evidence to help patient achieve their personal goals. Goals are organized into 4 distinct categories: 1) prevention of premature death and disability, 2) maintenance or improvement of QOL, 3) maximization of personal growth and development, and 4) preparation for a good death. ${ }^{23}$ GDHC differs from most patientcentered care approaches by creating a unique interplay between the patient, the clinician, and the goals developed collaboratively by both the patient and clinician. ${ }^{24}$

The present study is the second in a series of studies designed to determine how to help patients and clinicians shift to a goal-directed approach, focusing on only the QOL goal category. In this prior study, we utilized previsit forms which included 3 QOL questions. Patients were able to express their QOL goals on the form. Physicians almost never addressed patients' QOL priorities but almost always addressed symptoms expressed on the control forms. ${ }^{25}$ Furthermore, the QOL data appeared to have a negative effect, reducing physicians' expression of empathy. Other studies have shown modest effects on physician-patient communication after pre-encounter priming for patients and clinicians, ${ }^{14}$ but no other studies have investigated interventions involving both patients and practitioners that can be easily integrated into primary care settings. In this study, we attempted to facilitate goal-directed patient-clinician discussions by priming patients with the same previsit QOL questions and adding a physician prompt to ask a QOL question taken from the form.

\section{Methods \\ Physician Recruitment}

Our study was conducted in the Department of Family and Preventive Medicine's faculty/resident practice at the University of Oklahoma Health Sciences Center. The Center's Institutional Review Board approved the study. Fourteen family physicians, including 6 faculty, 5 third-year residents, and 3 second-year residents agreed to participate and provided written consent. All physicians who had more than 3 half-days of clinic per week during the data collection period were included in the study. First-year residents were excluded as the data collection took place during the first month of the academic year.

Participating clinicians were told that the purpose of the study was to assess the quality of communication in patient-clinician encounters using goal-directed prompts. The control physicians were told that the prompts were new previsit forms that patients would fill out before their visits. Intervention physicians were told that the prompts were the previsit forms plus the following question they were prompted to ask during the patient encounter: "What things are you unable to do because of your health problems today?" A cue card with the question was given to the physician with the previsit form. Neither physicians nor patients were given any other training in GDHC or communication.

The physicians were assigned to 1 of 2 study groups. The first was a pre/post group in which 3 physicians (1 attending, 1 second-year resident, and 1 third-year resident) each participated in 5 control encounters and 5 intervention encounters in random order. The second group included eleven physicians ( 5 faculty, 4 third-year residents, 2 secondyear residents) who were randomly assigned to either control or intervention arms for either 2 or 3 encounters. This design was used to facilitate scheduling of the video-tapings. The academic clinic is designed with 4 clinic wings. Only 1 room in each wing has built-in cameras that are discreet 
and allow for audio and video recording encounters.

\section{Patient Recruitment}

To be included, patients had to be at least 18 years old, speak English as their primary language, and have at least 1 chronic medical condition listed on their problem list. The research assistants reviewed the schedule with the physicians before the clinic session began and patients who did not meet criteria were excluded. Over a 6-week period, all regularly-scheduled patients who met the inclusion criteria were approached by the research assistants and those who were amenable were enrolled immediately before their scheduled visit and verbal and written inform consent was obtained. A total of 60 patients agreed to take part in the study.

After enrollment, patients were placed into 1 of 4 rooms which have embedded ceiling cameras and audio equipment, and the research assistants gave the previsit form directly to the patients to complete as they waited for their appointment. The form began with the clinic's usual previsit questions that included a record of recent emergency department (ED) visits, hospitalizations, other visits to health care providers, medication changes, initiation of home health services, or any other major life changes. It also included 3 goal-directed questions that were developed over years of clinical practice by the founders of GDHC and were validated in our prior study: 1) What things are you unable to do as a result of your health problems? 2) What other things would you like to be able to do that you cannot do now? 3) What activities give purpose to your life? ${ }^{28}$ The completed questionnaire was placed inside the visit folder for clinician review during the visit in the same manner the clinic's usual previsit form is reviewed.

\section{Video Analysis}

The research assistants and Becky A. Purkaple conducted separate analyses on the data obtained from the 2 different study groups. The 2 primary outcome measures were: 1) Was patient-expressed QOL information discussed during the encounter (yes/no)? and 2) Was that QOL information used in medical decision making (yes/no)? QOL information was defined as any phrases taken from the previsit surveys or the keywords "quality of life," "function(ing)," "ability," and "goal(s)." Medical decision making was defined using the Centers for
Medicare Services' definition: any decision that elicits a diagnosis, prognosis, therapy, or further testing based on the application of clinician knowledge to patient information. ${ }^{26}$ Therefore, to meet our outcome criterion, the physicians had to use QOL information to make a diagnosis, discuss prognosis, change/modify therapy, or instigate further testing. We did not differentiate based on medical complexity. There were no discrepancies between the research assistants and Becky A. Purkaple (Cohen $\mathrm{k}=1$ ). The transcripts of the encounters were reviewed by Zsolt J. Nagykaldi as well with no discrepancies. Results in the randomly assigned patient visit group were analyzed using Fischer's exact test. Results from the prepost repeated measure group were analyzed using $\mathrm{McNe}$ mar's test.

\section{Secondary Outcome Measures}

All videos were also scored with the Modified Flanders Interaction Tool, a method that was initially developed to assess teacher communication in the classroom and has since been used to analyze patient-centered provider communication especially in medical training. ${ }^{27-30}$ The assessment captured the content of patient-clinician encounters in 3 -second intervals using a 10-option categorical model. From that data, we calculated the percent of clinician talk time, the percent of patient talk time, and the percent of silence. The Flanders scale can be further categorized as direct communication and indirect communication. Direct communication is more authoritative and limits responses, while indirect communication allows for more freedom and inclusion of patient ideas. Two research assistants were trained by Becky A. Purkaple to score the videotapes using standard patient videos before data collection began. The videos were scored by the research assistants with 1 scoring the prepost and the other scoring the randomized group.

\section{Results}

Participating patient demographics are shown by study group in Table 1 . Only 3 of the 60 enrolled patients opted to leave the previsit questionnaire entirely blank. A minority (Q1: 15\%; Q2: 12\%; and Q3: 5\%) failed to answer 1 or more of the previsit questions.

Table 2 provides typical examples for patient answers from both groups. Transcripts of 2 inter- 
Table 1. Patient Characteristics

\begin{tabular}{lcccc}
\hline Characteristic & Control & Intervention & Total & $P$-Values \\
\hline Age (SD) & $61(13)$ & $51(21)$ & $57(17)$ & $.13^{*}$ \\
Male & $42 \%$ & $36 \%$ & $38 \%$ & $.38^{\dagger}$ \\
Female & $58 \%$ & $64 \%$ & $62 \%$ & $.38^{\dagger}$ \\
Caucasian & $45 \%$ & $43 \%$ & $43 \%$ & $.64^{\dagger}$ \\
African American & $52 \%$ & $46 \%$ & $47 \%$ & $.64^{\dagger}$ \\
Other & $3 \%$ & $1 \%$ & $<1 \%$ & $.64^{\dagger}$ \\
\hline
\end{tabular}

SD, standard deviation.

${ }^{*}$ Comparison of Means.

${ }^{\dagger} \chi^{2}$.

vention encounters, 1 in which QOL information was used in medical decision making and 1 in which it was not, are listed in Table 3.

During control encounters, none of the clinicians in either study group referenced the previsit patient survey answers or commented on the QOL issues raised even though they could be seen on videotape looking at the surveys. The QOL information was verbally expressed by only 1 patient. In that case, the clinician did not react to the information, and it was not used in medical decision making.

In the intervention encounters, despite a verbal reminder and the written prompt, physicians asked the QOL question in only $22(73 \%)$ of the 30 encounters. Five (36\%) of the 11 physicians in the randomized group rephrased the question to lead the patient toward a negative answer (ie, "There is nothing you cannot do because of your health problems, right?"). Even then, only 1 patient responded that he/she had no limitations. That patient's health issues included sickle cell disease with frequent emergency department (ED) and hospital visits that made it difficult to care for her 3 small children and manage her current high-risk pregnancy. When the question was not asked by the physicians, 3 patients brought up QOL concerns themselves (1 en-

Table 2. Patient Responses to Prompt Question

\begin{tabular}{|c|c|c|}
\hline Questions & Control Group & Intervention Group \\
\hline \multirow[t]{4}{*}{ Q1 } & $\begin{array}{l}\text { Pain and arthritis in hands limits times when I can use } \\
\text { hands and pick things up }\end{array}$ & $\begin{array}{l}\text { I can't do normal adult things like workout, hangout } \\
\text { with friends, and enjoy life because my weight and } \\
\text { legs }\end{array}$ \\
\hline & Seeing, hearing, teeth, independence & $\begin{array}{l}\text { Twist the lids off jar. Decreased grip or hand } \\
\text { strength }\end{array}$ \\
\hline & $\begin{array}{l}\text { Just live like I want to workout play ball play with my } \\
\text { kids }\end{array}$ & Walking or playing with grandchildren, house work \\
\hline & $\begin{array}{l}\text { Work, walk long distances, stand long periods of time, } \\
\text { and sometimes unable to just get out of bed }\end{array}$ & \\
\hline \multirow[t]{5}{*}{ Q2 } & Take road trips & $\begin{array}{l}\text { Get up in my chair better from the floor, get into } \\
\text { bed and the shower without someone holding my } \\
\text { chair }\end{array}$ \\
\hline & Drive a car, climb a ladder & Fishing, hunting, walking comfortably \\
\hline & Walk a whole mile, walk faster and climb steps & $\begin{array}{l}\text { Walk and see better, would like to read, would like } \\
\text { to dance }\end{array}$ \\
\hline & $\begin{array}{l}\text { Go on a vacation without having problems with my } \\
\text { legs and feet }\end{array}$ & \\
\hline & Sex & \\
\hline \multirow[t]{4}{*}{ Q3 } & Time with family, church & Hanging with friends and family; crafting \\
\hline & $\begin{array}{l}\text { Music, talking about positive aspects, my family, } \\
\text { poetry }\end{array}$ & Wheelchair basketball; sports being around people \\
\hline & Music, spiritual ministries & Books, my religion, my grandkids \\
\hline & $\begin{array}{l}\text { Spending time with family and friends, learning new } \\
\text { things, travel, social interactions }\end{array}$ & \\
\hline
\end{tabular}


Table 3. Transcripts of QOL Discussions from

\section{Recorded Encounters}

Conversation 1:

Provider: What can you not do because of your health problems today?

Patient: Uh, well, taking long trips. And, long walks. And that's about it. And working.

Provider: Why is that?

Patient: My back, the scoliosis.

Provider: How long ago were you diagnosed?

Patient: It's been some years I was born with it and I had rods in my back

Patient: And so that, let me see. At 13 years. Gotcha. 9 scoliosis surgeries due to congenital scoliosis and seizures since 2003. And what's your living situation?

Conversation 2:

Physician: There is nothing you cannot do because of your health problems, right?

Patient: No. Nothing is really stopping me. I mean, sometimes I recently started feeling. I guess it is side effects of the vitamin $\mathrm{D}$ deficiency like being really, really tired. Unbearably tired. Like in the middle of the day, barely being able to keep my eyes open tired.

Provider: Wow

Patient: And like last week it was the first week that it started to really like affect me. And I have been feeling these symptoms of stuff and I hadn't really felt them until just last week

Provider: Anything about last week that was you think was causing you to feel tired all the time?

Patient: Like social wise?

Provider: Yeah?

Patient: No, nothing. Regular week.

Provider: And have you been eating pretty normally?

Patient: Yes.

Provider: So, what happens to you when you get unbearably tired in the middle of the day? How do you deal with that?

Patient: I have to lay down or at least lay my head down

Provider: For how long?

Patient: Until I can manage to keep my eyes open.

Physician: How are you sleeping?

Patient: I wake up coughing and toss and turn all night.

Physician screens for sleep apnea and orders sleep study.

QOL, quality-of-life discussion.

counter in the pre/post group, 2 in the randomized group).

QOL was introduced more often during intervention encounters than in control encounters $(P<$ 0.05; see Table 4 and Table 5). However, QOL information influenced decision making in only 4 of the 30 (13\%) intervention encounters. One physician in the pre/post group and 2 physicians in the random group used QOL in clinical decision making. In 1 of those encounters, the discussion of
QOL limitations resulting from fatigue led to a physician-directed discussion of sleep hygiene and a possible sleep study. In another, the physician leveraged the patient's weight-related functional limitation to discuss healthy exercise and dietary options. One patient initially refused recommended laboratory tests, and the clinician used her QOL concerns to encourage collaboration with testing. In the fourth case, the discussion of QOL issues prompted the physician to refer the patient to a new subspecialist for further workup. However, there was no statistical difference between the control and intervention groups in terms of frequency of incorporation of QOL concerns into medical decision making.

The results of the Modified Flanders Analyses are shown in Tables 4 and 5. There was no difference between the 2 groups in patient talk time, clinician talk time, direct communication, indirect communication, or silence.

\section{Discussion}

This study confirms our previous findings that clinicians seem to be either poorly equipped or otherwise hesitant to address patient questions or concerns about QOL priorities. In more than a quarter of intervention encounters, the QOL prompt question was not even asked. In follow up, 1 clinician voiced some concern that the prompt was not pertinent to the particular patients and would have interrupted the visit flow. Only 4 of the 30 visit recordings indicated the use of patient-generated QOL content in medical decision making in the intervention group, which was statistically no more often than in the control group.

Patients on the previsit forms were able to identify health-related meaningful life activities and deficits in functioning (See Table 2), but were hesitant to bring up them up unprompted. The forms in this study were completed at similar rates to our previous study where the QOL form had an $87.5 \%$ completion rate, and the control form had a $75 \%$ completion rate. When prompted by their physicians, patients readily discussed health-related QOL concerns. It is important to understand the issues that prevent clinicians from engaging in QOL data because eliciting goal-directed conversations may lead to more tailored and effective care and has been shown that enabling patients in such a way increases adherence to evidence-based guidelines and patient satisfaction. ${ }^{31-36}$ 
Table 4. A Comparison of Outcomes in the Pre-Post, Repeated Measures Group $(\mathrm{n}=60)$

\begin{tabular}{|c|c|c|c|}
\hline & Control Group $(\mathrm{n}=15)$ & Intervention Group $(\mathrm{n}=15)$ & Significance $(P)$ \\
\hline Patient QOL goals mentioned & 1 & 11 & $0.0378^{*}$ \\
\hline Patient QOL goals used in clinical decision making & 0 & 2 & $0.1334^{*}$ \\
\hline \multicolumn{4}{|l|}{ Modified Flanders } \\
\hline Physician talk & $48.9 \%$ & $47.0 \%$ & $0.343^{\dagger}$ \\
\hline Patient talk & $33.9 \%$ & $35.2 \%$ & $0.373^{\dagger}$ \\
\hline Direct communication & $9.8 \%$ & $7.5 \%$ & $0.493^{\dagger}$ \\
\hline Indirect communication & $27.5 \%$ & $27.5 \%$ & $0.275^{+}$ \\
\hline Silence & $17.5 \%$ & $17.8 \%$ & $0.260^{\dagger}$ \\
\hline
\end{tabular}

QOL, quality-of-life discussion.

*McNemar's test.

${ }^{\dagger}$ Paired $t$-test.

The conversations between the physicians and patients showed interesting patterns of communication. When patients answered their physician's QOL question, the physicians would engage, but could not transition the discussion into medical decision making. For instance, 3 patients discussed that traveling was difficult due to their health conditions (anxiety, morbid obesity) and those 3 physicians did spend time discussing their desired travel plans and the barriers to travel that these conditions impose. However, they did not tie patients' desired to travel into their health plan which could have been, for example, through weight loss, attending counseling, medication compliance, or physical therapy. The conversation in Table 3 highlights how physicians tended to medicalize the QOL issue and then change the subject, which occurred in a majority of encounters.

The issue of how to encourage goal-directed communication in the patient-clinician encounters remains elusive. Over a third of the physicians who asked the prompted question altered it to a leading question, suggesting that there are perceived barriers to QOL conversations. In a discussion group after the study was completed, many physicians discussed concerns over time constraints that they felt limited their ability to engage in QOL conversations. It is interesting to note that the 4 QOL conversations that included medical decision making had a median of 17 minutes (range, 13 to 22 minutes). The control encounters had a median time of 15 minutes (range, 7 to 43 minutes) and the intervention encounters that did not include medical decision making had a median of 19 minutes (range, 7 to 31 minutes). Our sample size is too small to make definitive claims about the time component, but it seems to suggest that QOL encounters can be performed efficiently within the clinic visit.

We posit that physicians may not engage in this conversation due to their problem-oriented mindset and training. Clinicians know how to use symptoms to generate a differential diagnosis but are

Table 5. A Comparison of Outcomes in the Random Clinician Assignment Group $(\mathrm{n}=\mathbf{3 0})$

\begin{tabular}{lccc}
\hline & Control Group (n=15) & Intervention Group (n = 15) & Significance $(P)$ \\
\hline Patient QOL goals mentioned & 0 & 13 & $\mathbf{. 0 1 8 9}^{*}$ \\
Patient QOL goals used in clinical decision making & 0 & 2 & $.285^{*}$ \\
Modified Flanders & & & \\
Physician talk & $44.1 \%$ & $44.8 \%$ & $.5920^{\dagger}$ \\
Patient talk & $36.7 \%$ & $36.2 \%$ & $.7015^{\dagger}$ \\
Direct communication & $6.1 \%$ & $6.0 \%$ & $.7862^{\dagger}$ \\
Indirect communication & $26.6 \%$ & $26.8 \%$ & $.7862^{\dagger}$ \\
Silence & $19.4 \%$ & $18.2 \%$ & $.7053^{\dagger}$ \\
\hline
\end{tabular}

QOL, quality-of-life discussion.

*Fischer's exact test.

${ }^{\dagger}$ Comparison of independent means with $t$-test. 
generally not taught how to incorporate QOL priorities into medical decision making. Patients, on the other hand seem ready and eager to discuss QOL issues.

A more robust intervention is needed to help physicians and patients incorporate QOL goals in decision making. Occupational therapists and other rehabilitation professionals, sports medicine clinicians, social workers, and many mental health professionals already operate in goal-direct frameworks, which could be adapted and integrated into general medical training, and some researchers are applying the same methods in geriatric populations. ${ }^{37}$ The standardized patient model could be adapted to train this communication skill. Continuing medical education could also be redesigned to include methods for effective goal assessment and collaborative goal setting with patients. In addition to updating professional training, systemic changes would also need to occur. It has been shown that electronic medical record prompts can be used in a variety of settings to alter clinician behavior. ${ }^{38}$ Billable codes (eg, The International Classification of Functioning, Disability, and Health) could be adopted to encourage goal-directed discussions and decision making as well.

Adoption of goal-directed care could not only help patients, but also clinicians. Primary care clinicians report high levels of burnout. ${ }^{39,40}$ While there are many contributing factors, one commonly cited reason is clinicians' feeling of disconnectedness from patients, whether due to time constraints, the dominance of the electronic medical record, or administrative tasks that now seem to rival direct patient contact time. ${ }^{41-43}$ GDHC offers a new way to create more meaningful personal connections between patients and health care professionals. Goal orientation could enable patients and practitioners to more effectively translate clinical guidelines into personalized care approaches. ${ }^{44}$ Rather than creating a new specialty, perhaps we simply need a new conceptual framework for primary care.

Our study has a number of limitations. The study was conducted in a single academic residency program, and all professionals were either faculty or residents in the same department. This may limit the diversity of clinician participants. For that reason, we attempted to maximize the number of clinicians in the study as well as differences in their age, gender, ethnicity, and clinical training. Physicians and patients were aware that they were being observed, which could have affected their behaviors (Hawthorne effect). We attempted to minimize this effect by recording both control and intervention encounters and by using subtle recording equipment that was already built into the teaching clinic. Regular, ongoing recording with professionally installed camera systems for resident teaching also limited the intrusiveness of the recording. Although the information provided to the clinicians about the study was purposely vague and the data analyst was blinded to group assignment, the verbalization of the intervention question, no doubt affected blinding. Our sample size (60 patients and 14 clinicians) and the observation arrangement (2 clinician groups) resulted in limited power to detect small differences. Lastly, our data collection window was over a period of 6 weeks and our intervention could have had a future effect that was not measured during our data collection window.

To see this article online, please go to: http://jabfm.org/content/ 33/1/71.full.

\section{References}

1. Chang S, Lee T. Beyond evidence based medicine. JAMA 2018;379(21).

2. Gutierrez C, Scheid P. The history of family medicine and its impact in US health care delivery. Leawood, KS: AAFP Foundation; 2002. Available from: http://www. aafpfoundation.org/online/etc/medialib/found/documents/ programs/chfm/foundationgutierrezpaper.Par.0001.File. tmp/foundation-gutierrezpaper.pdf. Accessed August 1, 2019.

3. Constand MK, MacDermid JC, Dal Bello-Haas V, Law M. Scoping review of patient-centered care approaches in healthcare. BMC Health Serv Res 2014; 14;271. Available from: http://www.biomedcentral. com/1472-6963/14/271.

4. Mead N, Bower P. Patient-centredness: a conceptual framework and review of the empirical literature. Soc Sci Med 2000;51:1087-110.

5. Institute of Medicine (US) Committee on Quality of Health Care in America. crossing the quality chasm: a new health system for the 21 st century. Washington, DC: National Academies Press; 2001.

6. Langberg EM, Dyhr L, Davidsen AS. Development of the concept of patient-centredness-A systematic review. Patient Educ Couns 2019;102: 1228-1236.

7. Bertakis KD, Azari R. Patient-centered care is associated with decreased health care utilization. J Am Board Fam Med 2011;24:229-39.

8. Jaen CR, Ferrer RL, Miller WL, et al. Patient outcomes at 26 months in the patient-centered medical 
home national demonstration project. Ann Fam Med 2010;8:S57-S67; S92.

9. Loh A, Simon D, Wills CE, Kriston L, Niebling W, Härter M. The effects of a shared decision-making intervention in primary care of depression: a clusterrandomized controlled trial. Patient Educ Couns 2007;67:324-332.

10. Schoenthaler A, Kalet A, Nicholson J, Lipkin M. Does improving patient-practitioner communication improve clinical outcomes in patients with cardiovascular diseases? A systematic review of the evidence. Patient Educ Couns 2014;96:3-12.

11. Stewart MA. Effective physician-patient communication and health outcomes: a review. CMAJ 1995; 152:1423-33.

12. Levack WMM, Weatherall M, Hay-Smith EJC, Dean SG, McPherson K, Siegert RJ. Goal setting and strategies to enhance goal pursuit for adults with acquired disability participating in rehabilitation. Cochrane Database Syst Rev 2015;7: CD009727.

13. Bombard Y, Baker GR, Orlando E, et al. Engaging patients to improve quality of care: a systematic review. Implement Sci 2018;13:98.

14. Dwamena F, Holmes-Rovner M, Gaulden CM, et al. Interventions for providers to promote a patientcentred approach in clinical consultations. Cochrane Database Syst Rev 2012;12:1-177.

15. Fix GM, VanDeusen Lukas C, Bolton RE, et al. Patient-centred care is a way of doing things: How healthcare employees conceptualize patient-centred care? Health Expect 2018;21:300-7.

16. Mold JW, Blake GH, Becker LA. Goal-oriented medical care. Fam Med 1991;23:46-51.

17. Mold JW, Hamm R, Scheid D. Evidence-based medicine meets goal-directed health care. Fam Med 2003;35:360-4.

18. Nagykaldi ZJ, Dave A, Kristof CJ, Watts TN, Utpala S, Wickersham E. Improving patient-clinician conversations during annual wellness visits. J Am Board Fam Med 2017;30:161-169.

19. Aronson L, Bautista CA, Covinsky K. Medicare and care coordination: expanding the clinician's toolbox. JAMA 2015;313:797-8.

20. Naik AD, Dyer CB, Kunik ME, McCullough LB. Patient autonomy for the management of chronic conditions: a 2-component reconceptualization. Am J Bioethics 2009;9:23-30.

21. Llanwarne NR, Abel GA, Elliott MN, et al. Relationship between clinical quality and patient experience: analysis of data from the English Quality and Outcomes Framework and the National GP Patient Survey. Ann Fam Med 2013;11:467-72.

22. Wilson IB, Cleary PD. Linking clinical variables with health-related quality of life. A conceptual model of patient outcomes. JAMA 1995;273: $59-65$.
23. Mold J. Goal-Directed health care: redefining health and health care in the era of value-based care. Cureus 2017;9:e1043.

24. Reuben DB, Tinetti ME. Goal-oriented patient care-An alternative health outcomes paradigm. N Engl J Med 2012;366:777-9.

25. Purkaple BA, Mold JW, Chen S. Encouraging patient-centered care by including quality-of-life questions on pre-encounter forms. Ann Fam Med, 2016; 14(3):221-226.

26. Dept of Health and Human Services' Centers for Medicare and Medicaid Services. Evaluation and management services. The Medicare Learning Network. August 2017. Available from: https://www.cms. gov/Outreach-and-Education/Medicare-LearningNetwork-MLN/MLNProducts/Downloads/eval-mgmtserv-guide-ICN006764.pdf. Accessed August 1, 2019.

27. Flanders NA. Interaction analysis in the classroom: a manual for observers. Ann Arbor, MI: University of Michigan; 1964.

28. Foster PJ. Verbal participation and outcomes in medical education. A study of third-year clinical discussion groups. Annu Conf Res Med Educ 1979;18: 233-238.

29. Kishi KI. Communication patterns of health teaching and information recall. Nurs Res 1983; $32: 230-5$.

30. Lyon HC Jr, Holzer M, Reincke M, et al. Improvements in teaching behavior at two German medical schools resulting from a modified Flanders interaction analysis feedback intervention process. Med Teach 2014;204;36:903-11.

31. Forestier B, Anthoine E, Reguiai Z, Fohrer C, Blanchin M. A systematic review of dimensions evaluating patient experience in chronic illness. Health Qual Life Outcomes 2019;2:1-14.

32. Nagykaldi Z, Yeaman B, Jones M, Mold JW, Scheid DC. HIE-i-Health information exchange with intelligence. J Ambul Care Manag 2013;37: $20-31$.

33. Stewart M, Brown JB, Donner A, et al. The impact of patient-centered care on outcomes. J Fam Pract 2000;49:796-804.

34. Fried TR, Tinetti M, Agostini J, Iannone L, Towle $\mathrm{V}$. Health outcome prioritization to elicit preferences of older persons with multiple health conditions. Patient Educ Couns 2011;83:278-82.

35. Griffin SJ, Kinmonth AL, Veltman MW, Gillard S, Grant J, Stewart M. Effect on health-related outcomes of interventions to alter the interaction between patients and practitioners: a systematic review of trials. Ann Fam Med 2004;2:595608.

36. Constand MK, MacDermid JC, Dal Bello-Haas V, Law M. Scoping review of patient-centered care approaches in healthcare. BMC Health Serv Res 2014; $14: 271$. 
37. Rueben DB, Jennings LA. Putting goal-oriented patient care into practice. J Am Geriatr Soc 2019;67: 1342-4.

38. Alagiakrishnan K, Wilson P, Sadowski CA, et al. Physicians' use of computerized clinical decision supports to improve medication management in the elderly-The Seniors Medication Alert and Review Technology intervention. Clin Interv Aging 2016:11;73-81.

39. Salvagioni DAJ, Melanda FN, Mesas AE, González AD, Gabani FL, De Andrade SM. Physical, psychological and occupational consequences of job burnout: a systematic review of prospective studies. PLoS ONE 2017:12(10);1-29.

40. Sinsky CA, Dyrbye LN, West CP, Satele D, Tutty M, Shanafelt TD. Professional satisfaction and the career plans of US physicians. Mayo Clinic Proc 2017:92(11);1625-1635.

41. Miltenburger C, Borgstrom F. Beyond product value-A holistic approach for value assessment. ISPOR 20th Annual European Congress, 2017; 573-576.

42. Sinsky C, Tutty M, Colligan L. Allocation of physician time in ambulatory practice. Ann Intern Med 2017;166:683-4.

43. Brown S, Gunderman RB. Viewpoint: enhancing the professional fulfillment of physicians. Acad Med 2006:81;577-82.

44. Singh Ospina N, Phillips KA, Rodriguez-Gutierrez $\mathrm{R}$, et al. Eliciting the patient's agenda-Secondary analysis of recorded clinical encounters. J Gen Intern Med 2018;1-5. 